\title{
Hizkuntzak burmuin elebidunean; zer erakusten du gaztelania-euskara elebidun afasiko baten kasu-azterketak?
}

\author{
(Languages in the bilingual brain; what does a case study \\ on Spanish-Basque bilingual aphasia reveal?)
}

\author{
Amaia Munarriz-Ibarrola \\ ELEBILAB, Euskal Hizkuntza eta Komunikazioa Saila, \\ Euskal Herriko Unibertsitatea UPV/EHU
}

amaia.munarriz@ehu.eus

Laburpena: Artikulu honetan Hizkuntzen antolaketa burmuin elebidunean: gaztelania-euskara elebidun afasiko baten kasu-azterketa [1] tesiaren emaitza nagusiak aurkezten dira. Tesi horren xedea da hizkuntzak eta hizkuntza-osagaiak elebidunen burmuinean nola antolatzen diren ezagutzea, eta horretarako gaztelania-euskara elebidun afasiko baten kasu-azterketa egin da. Artikulu honetan aurkezten da nola azaleratzen diren hizkuntza-arazoak bi hizkuntzetan hiztegian eta maila morfosintaktikoan. Emaitzek erakutsi dute afasiak ez diela eragin hizkuntza-osagaiei modu berean; maila semantikoaren eta fonologikoaren artean disoziazioak daude, eta baita egitura morfosintaktiko batzuen kasuan ere. Halaber, arazoak ez dira maila berekoak euskaraz eta gaztelaniaz, morfosintaxian aurkitutako alde kualitatiboek eta maila lexikoko alde kuantitatiboek erakutsi dutenez. Oro har, emaitzek berresten dute hizkuntzak eta hizkuntza-osagaiak hein batean bereizita daudela elebidunen burmuinean.

Hitz gakoak: afasia elebiduna, kasu-azterketa, psikolinguistika, euskara, gaztelania.

Abstract: The aim of this article is to present the main findings of the dissertation Language organisation in the bilingual brain: a case study on Spanish-Basque bilingual aphasia [1]. The goal of that dissertation is to move towards an understanding of how languages and linguistic components are organised in the bilingual brain by means of a case study of a Spanish-Basque bilingual with aphasia. In this paper, we present language difficulties arising at the lexical and morphosyntactic level in both languages. The results reveal that the brain lesion does not impair linguistic levels in the same manner; dissociations were observed between the semantic and the lexical levels, and also within certain morphosyntactic structures. Additionally, the impairment does not 
affect Spanish and Basque to the same extent. This is evidenced by qualitative differences at the morphosyntactic level and by quantitative differences at the lexical level. These results support the distinction of languages and linguistic components in the bilingual brain.

Keywords: bilingual aphasia, case study, psycholinguistics, Basque, Spanish.

\section{SARRERA}

Artikulu honen xedea da honako doktorego-tesi honetako ideia nagusiak aurkeztea: Hizkuntzen antolaketa burmuin elebidunean: gaztelaniaeuskara elebidun afasiko baten kasu-azterketa [1].

Afasia deritze burmuineko lesio baten ondorio diren hizkuntza-arazoei. Arazo horiek era askotakoak izan daitezke: ekoizpen edota ulermen-arazoak, ahozkoari edota idatzizkoari dagozkionak, edo hizkuntzak bereizteko ezintasuna elebidunen kasuan, adibidez. Hizkuntza-arazoen behaketak aukera ematen du hiztunak «galdua» duen hizkuntzarako gaitasuna nolakoa den aztertzeko; eta, aldi berean, ikusteko zein beste (azpi)gaitasunetan ez duen eraginik izan ezintasuna sortu duen burmuineko lesioak. Bestela esanda, afasiaren ondorio diren urradura zehatzetan oinarrituta inferi daiteke zein diren hizkuntza prozesatzean gertatzen diren urrats eta eragiketak, eta horrek aukera ematen du sistema kognitiboaren eta hizkuntzaren arkitektura ezagutzeko (ikuspegi orokor baterako, ikus [2]). Elebidunen kasuan, gainera, sintomak bi hizkuntzetan aztertzeak ahalbidetzen du behatzea lesioak azpimaila beretan eragina izan duen bietan. Alderaketa horrek aukera ematen du egiaztatzeko elebidunaren burmuinean hizkuntza bakoitzak bere esparrua duen ala bi hizkuntzek osagaiak partekatzen dituzten semantikan, fonologian, sintaxian eta beste hizkuntza-mailetan.

Aipatutako tesiaren helburu nagusia da hizkuntzak eta hizkuntza-osagaiak elebidunen burmuinean nola antolatzen diren ezagutzea, eta horretarako datu bila AF deituriko gaztelania-euskara elebidun afasiko baten kasu-azterketa da abiapuntu enpirikoa. Afasiko elebidunaren hizkuntza-jokabidea xeheki ikertzeko hizkuntza-arazoak nola azaleratzen diren behatu da bi hizkuntzetan, ariketa ugariren bidez. Hona hemen erantzun nahi diren ikerketa-galdera nagusiak: a) zein dira afasiaren sintomak euskaraz eta gaztelaniaz?, eta b) modu eta neurri berean azaleratzen al dira hizkuntzaarazoak elebidunen bi hizkuntzetan?

Artikuluaren egituraketari dagokionez, sarrera honen ondoren, afasia elebidunaren literaturari gainbegiratu orokor bat emango zaio, eta, horrekin batera, lan honen helburuak eta aurreikuspen nagusiak azalduko dira. Ondoren, 3. atalean euskara-gaztelania elebidun afasikoaren kasu-azterketa aurkezten da: parte-hartzaileak, datu-bilketa eta datuen analisia. 4. atala emaitza nagusiei eskaintzen zaie; bertan aurkezten dira hiztegian eta maila 
morfosintaktikoan azaleratzen diren sintoma nagusiak. Atal horren ondotik, 5. atalean emaitza horien eztabaida orokorra aurkezten da; eta, bukatzeko, 6. atalean, ondorio nagusiak.

\section{AFASIA ELEBIDUNA}

Afasia duten hiztunengan agertzen diren hizkuntza-arazoak ez dira hizkuntza-maila guztietan azaleratzen beti $[3,4]$, ezta hiztun elebidun edo eleaniztunen hizkuntza guztietan ere [5]. Hitzak eskuratzeko arazoak dituzten afasikoen azterketetan, adibidez, oso urradura espezifikoak eta disoziazio argiak aurkitu dira [6]. Horren adibide gisa aipa daitezke maila semantikoaren eta fonologikoaren arteko disoziazioak [7, 8], eta, maila fonologikoaren barruan, lexiko-fonologiko eta lexiko osteko maila fonologikoaren arteko disoziazioak [9].

Maila morfosintaktikoan azaleratzen diren sintomak agramatismo sindromearen aterkipean biltzen dira. Honako ezaugarri hauek dituen hizkuntza-arazo gisa definitzen da agramatismoa [10]: hitz-jario txikia, hizketarako abiadura motela, eta esaldi labur eta sinpleak; gramatikalki urria, ezaugarri sintaktiko eta morfologikoei dagokienez; morfema gramatikalen ezabaketa edo ordezkapena, eta hitz-hurrenkera egoki erabiltzeko arazoak. Agramatikoena «hizketa telegrafiko»tzat jotzen da; oro har, kategoria eta morfema funtzionalen (determinatzaileak, aditz laguntzaileak, kasua, genero-, pertsona- eta numero-komunztadura, adb.) artean huts eta ezabaketa gehiago ageri dira kategoria eta morfema lexikoen (izenak, adjektiboak, aditzak, adb.) artean baino. Esaldi mailako arazoei dagokienez, zenbait egitura konplexurekin arazoak agertzen dira ekoizpenean edota ulermenean; esaterako, erlatibozko perpausekin, galderazko perpausekin, eta egitura pasibo eta topikalizatuekin. Egitura horietan, gainera, subjektu-objektu asimetriak aurkitu dira hainbat hizkuntzatan. Hau da, hizkuntza gehienetan subjektuzko egiturak objektuzkoak baino hobeto ekoizten edota ulertzen dira $[4,10]$. Horrez gain, hainbat hizkuntzatako hiztun afasikoekin egindako ikerketek erakutsi dute sintomak hein handi batean hizkuntzen ezaugarrien araberakoak ere badirela [11, 12].

Elebidun eta eleaniztunen kasuan, bestalde, irudia konplexuagoa da; arazoak ez dira beti hizkuntza guztietan azaleratzen, eta berreskuratzea ere ez da sarritan maila eta mota berekoa izaten bi hizkuntzetan $[5,13]$. Bi hizkuntzen alderaketari dagokionez, ohikoena da nahasmendua paraleloa izatea eta modu antzekoan berreskuratzea [14]. Hau da, bi hizkuntzak kaltetzen dira (maila bertsuan); eta, ondorioz, lesioaren ondoren hizkuntza-gaitasunari dagokionez, bi hizkuntzen artean dagoen (des)berdintasuna lesioaren aurretik zegoenaren antzekoa izaten da. Gehienetan, gainera, berreskuratzea ere paraleloa izan ohi da, hots, bi hizkuntzetan gertatzen da an- 
tzera [15]. Halere, beste kasu batzuetan ikusi da hizkuntza bat bestea baino gehiago kaltetzen dela edo, biak antzera kaltetu ondoren, bietako bat bestea baino hobeto berreskuratzen dela [16]. Hain zuzen, nahasmendu eta berreskuratze ez-paraleloen kasuek erakutsi dute hein batean sare desberdinak dituztela hizkuntzek burmuinean [14]. Salbuespenak salbuespen, urradura eta berreskuratze paraleloak ohikoago dira tipologikoki antzekoak diren hizkuntzetan (hizkuntzen arteko efektuen ondorioz, adituen ustez) [17-19], eta ez-paraleloak tipologikoki desberdinak direnetan [20, 21].

\subsection{Ikerketa-galderak eta aurreikuspenak}

Hona tesiko ikerketa-galdera eta aurreikuspen nagusiak:

\section{a) Zein eta nolakoak dira afasiaren sintomak euskaraz eta gaztelaniaz?}

Afasiari lotutako hizkuntza-arazoek hizkuntza-osagaiei eta -modalitateei modu diferentean eragitea aurreikusten dugu. Oro har, euskaraz eta gaztelaniaz beste hizkuntzetako sintoma berak azaleratzea espero dugu; adibidez, hitzak eskuratzeko arazoak edota kategoria eta morfema gramatikalak erabiltzeko arazoak. Hiztegi mailan, hitzak eskuratzeko arazoek maila semantiko eta fonetiko-fonologikoari modu desberdinean eragitea aurreikusten da; esaterako, maila semantikoa kaltetu gabe egotea eta maila fonetiko-fonologikoa urratuta egotea, edo alderantziz. Maila morfosintaktikoan, erlatibozko edo galderazko esaldi konplexuekin ekoizpen- edota ulermen-arazoak aurreikusten dira, eta horietan, subjektu-objektu asimetriak.

\section{b) Modu eta neurri berean azaleratzen al dira afasiaren sintomak elebidunen bi hizkuntzetan?}

Gure hipotesia da antzekotasun gehien azaleratuko direla bi hizkuntzen artean antzekoen diren hizkuntza-maila eta -egituretan. Egitura fonologikoari begiratuta, maila segmentalean euskarak eta gaztelaniak antzeko inbentario fonologikoa dute. Aldiz, egitura morfosintaktikoan aldeak oso nabarmenak dira: euskara OV hizkuntza da, eta kasu-sistema ergatibo-absolutiboa du; gaztelania, berriz, VO hizkuntza da, eta kasu-sistema nominatibo-akusatiboa du. Hortaz, euskara-gaztelania elebidunengan jokabide antzekoagoa aurreikus daiteke fonologian morfosintaxian baino.

\section{KASU-AZTERKETA}

\subsection{Parte-hartzaileak}

AF emakumezkoa aldibereko elebiduna da; euskara eta gaztelania dira beraren lehen hizkuntzak, biak etxean jaso zituen hasiera-hasieratik. 39 ur- 
terekin burmuinaren ezker-hemisferioan garuneko hodietako istripu hemorragikoa izan zuen, eta azterketa klinikoan Broca afasiko gisa diagnostikatu zuten. Ikerketa AFren istripua gertatu eta handik 5 urtera hasi zen, AF fase kronikoan zegoenean. Ikerlan honetan, AFren kasu-azterketako emaitzekin batera, sexuari, adinari, ikasketa-mailari eta profil linguistikoari dagokienez, beraren antzeko ezaugarriak dituen kontrol elebidun baten emaitzak aurkezten dira. 1. taulan ikus daitezke parte-hartzaile bi horien ezaugarri nagusiak.

1. taula. Parte-hartzaileen ezaugarrien laburpena.

\begin{tabular}{|l|l|l|}
\hline & AF & Kontrola \\
\hline $\begin{array}{l}\text { Adina } \\
\text { (hizkuntza-azterketa hastean) }\end{array}$ & 45 & 43 \\
\hline Time post Onset & 5 urte 9 hil. & \\
\hline Sexua & emakumea & emakumea \\
\hline Esku nagusitasuna & eskuina & eskuina \\
\hline Ikasketa-maila & goi mailako ikasketak & goi mailako ikasketak \\
\hline Lanbidea & hizkuntza-irakaslea & hizkuntza-irakaslea \\
\hline Lehen hizkuntza(k) & $\begin{array}{l}\text { euskara } \\
\text { gaztelania }\end{array}$ & $\begin{array}{l}\text { gaztelania } \\
\text { euskara }\end{array}$ \\
\hline $\begin{array}{l}\text { Beste hizkuntza(k) } \\
\text { Ezagutu }\end{array}$ & (frantsesa) & $\begin{array}{l}\text { (frantsesa) } \\
\text { ingelesa }\end{array}$ \\
\hline Ikusmen-arazoak & bai (zuz.) & bai (zuz.) \\
\hline Entzumen-arazoak & ez & ez \\
\hline Etiologia & GHI & Broca afasia \\
\hline Afasia sailkapena & (fuli & \\
\hline
\end{tabular}

AFren hizkuntza-arazoei dagokienez, logopedaren lehen behaketan adierazten zen ulermena mantentzen zuela eta ekoizpena ukitua zuela gaztelaniaz (moteltasuna, hitzak gogoratzeko eta izendatzeko zailtasuna, etab.). Euskaraz ez zitzaion hizkuntza-azterketarik egin, nahiz eta txostenetan adierazi elebiduna zela. AFk berak hala hautatuta, hizkuntza-errehabilitazioa gaztelaniaz egin zuen urtebetez. Hizkuntza-errehabilitazioa, hasieran, astean hirutan jaso zuen ordu erdiko saiotan, eta ondoren astean bitan. 
AFren hizkuntza-gaitasuna eta -erabilerari buruzko informazioa autoebaluazio-galdetegi baten bidez lortu da [1] (2. taulan aurkezten da informazio nagusia laburtuta). Erabilerari dagokionez, lesioaren aurretik egunero erabiltzen zituen euskara zein gaztelania (lanean nahiz familiartean, ahoz nahiz idatziz), eta bietan gaitasun handia zuen (EGA edukitzea har liteke horren adierazgarri euskaraz), nahiz eta gaztelania zuen hizkuntza nagusitzat (kontrolak ere bai). Lesioaren ondoren gaztelania erabili du nagusiki bere egunerokoan.

2.taula. AFren hizkuntza-gaitasunaren autoebaluazioa.

\begin{tabular}{|c|c|c|c|c|c|c|c|c|c|}
\hline & \multicolumn{2}{|c|}{ Ulermena } & \multicolumn{2}{|c|}{ Irakurmena } & \multicolumn{2}{|c|}{ Ahozko ekoizpena } & \multicolumn{2}{|c|}{ Idatzizko ekoizpena } & \multirow{2}{*}{$\begin{array}{c}\text { Hizkuntzarik } \\
\text { erosoena }\end{array}$} \\
\hline & $G$ & $E$ & $G$ & $E$ & $G$ & $\boldsymbol{E}$ & $G$ & $E$ & \\
\hline Lesioaren aurretik & oso ona & oso ona & oso ona & oso ona & oso ona & ona & ona & ona & gaztelania \\
\hline Lesioa izan berritan & oso ona & oso ona & oso ona & ona & ez gai & ez gai & eskasa & eskasa & bat ere ez \\
\hline Fase kronikoan & oso ona & oso ona & oso ona & oso ona & oso ona & eskasa & ona & eskasa & gaztelania \\
\hline
\end{tabular}

\subsection{Datu-bilketa}

AFren hizkuntzaren azterketa luzetarako datu-bilketaren bidez osatu zen. 20 saiotan euskarazko eta gaztelaniazko hizkuntza-gaitasuna behatu zen zehaztasunez, honako hiru metodo hauek konbinatuz: behaketa bidezko metodoak, afasia aztertzeko bateria orokorrak eta ariketa esperimentalak. Ariketa mota horiek erabiltzearen helburua da, batetik, datu ahalik eta naturalenak biltzea (behaketa bidezko metodoak) eta, bestetik, behaketa bidez nekez azter daitezkeen egitura linguistiko zehatzagoak ikertzea (bateria orokorren eta ekoizpen- eta ulermen-ariketa esperimentalen bidez). Parte-hartzaileei ariketa guztiak euskaraz eta gaztelaniaz eginarazi zitzaizkien antzeko materialekin. 3. taulan ikus daitezke tesiko datu-bilketaren ezaugarri orokorrak ${ }^{1}$.

Artikulu honetan, hitz-mailako eta maila morfosintaktikoko emaitza nagusiak aurkezten ditugu bereziki. Horretarako, hiru ariketa-mota baliatu dira (3. taula, azken zutabea): a) hitzen ekoizpena aztertzeko ohikoa den irudiak izendatzeko ariketa bat, b) esaldi-mailako ekoizpena aztertzeko bi elizitazio-ariketa (erlatibozkoetarako bata, galderetarako bestea) eta c) ulermena aztertzeko esaldi-irudiak parekatzeko bina ariketa (erlatibozkoetarako bata, galderetarako bestea).

1 Tesian luzetara aztertutako ariketak L baten bidez adierazi dira 3. taulan. Behaketa bi hizkuntzetan egin zen ariketa gehienen kasuan. Saio bakoitzean saioaren lehen zatia hizkuntza batean egiten zen, eta bigarrena bestean; hurrengo saioan, hizkuntzen hurrenkera alderantzizkoa zen. Ariketa esperimentalen kasuan, bereziki irudi berberak baliatzen zirenean, bi saiotan egiten ziren. Lehenik, hizkuntza batean (adb. gaztelaniaz) egiten zen lehen atala, eta gero bestean (euskaraz), bigarren atala. Gutxienez astebete igaro ondoren, lehen atala egiten zen aurrekoan egin ez zen hizkuntzan (euskaraz), eta gero bigarrena bestean (gaztelaniaz). 
3. taula. Datu-bilketaren ezaugarri orokorrak.

\begin{tabular}{|c|c|c|c|c|}
\hline \multicolumn{2}{|c|}{ Datuak biltzeko metodoak } & Ariketak & Tesian & Artikuluan \\
\hline \multirow{2}{*}{\multicolumn{2}{|c|}{ Hizketa erdi-espontaneoa }} & Hizketa espontaneoa & $\bullet$ & \\
\hline & & Irudien deskribapena & $\bullet \mathrm{L}$ & \\
\hline \multirow{5}{*}{\multicolumn{2}{|c|}{ Hizkuntza-bateria orokorrak }} & Bateria orokorra $(\mathrm{CNL})$ & - & \\
\hline & & Diskriminazio fonologikoa (EPLA) & $\bullet$ & \\
\hline & & Irakurtzea (EPLA) & - & \\
\hline & & Errepikatzea (EPLA) & $\bullet$ & \\
\hline & & Idaztea (EPLA) & $\bullet$ & \\
\hline \multirow{13}{*}{$\begin{array}{l}\text { Ariketa } \\
\text { esperimentalak }\end{array}$} & \multirow[t]{4}{*}{ Hiztegia } & Testuak ozenki irakurtzea & $\bullet \mathrm{L}$ & \\
\hline & & Hitzak itzultzea & $\bullet$ & \\
\hline & & Galde-erantzun ariketa & $\bullet$ & \\
\hline & & Irudiak izendatzea & $\bullet \mathrm{L}$ & $\bullet$ \\
\hline & \multirow[t]{9}{*}{ Morfosintaxia } & Morfologiako ariketa & $\bullet$ & \\
\hline & & Irudien deskribapena: erlatibozkoak & - & $\bullet$ \\
\hline & & Esaldi-irudiak parekatzea: erlatibozkoak1 & $\bullet$ & \\
\hline & & Esaldi-irudiak parekatzea: erlatibozkoak2 & $\bullet$ & $\bullet$ \\
\hline & & Rol-jokoak: galde-perpausak $1,2,3$ & $\bullet$ & \\
\hline & & Elizitazioa: galde-perpausak & $\bullet$ & $\bullet$ \\
\hline & & Esaldi-irudiak parekatzea: galde-perpausak & $\bullet$ & $\bullet$ \\
\hline & & Esaldi-irudiak parekatzea: askotariko hurrenkerak & $\bullet$ & \\
\hline & & Esaldi-irudiak parekatzea (CNL) & $\bullet$ & \\
\hline
\end{tabular}

Irudiak izendatzeko ariketan, hainbat kategoria semantikotako 260 irudi [22] aurkeztu zitzaizkien parte-hartzaileei bina saiotan (hizkuntza bakoitzean). Parte-hartzaileek irudia izendatu behar zuten, hau da, irudian ikusten zutena zer zen esan behar zuten (adb. sagarra).

Elizitazio-ariketetan parte-hartzaileei irudiak aurkezten zitzaizkien, eta esaldi mota jakin bat ekoitzarazten aldi bakoitzean. Parte-hartzaileek honako egitura sintaktiko hauek ekoiztea bilatzen zen: erlatibozko perpausak (subjektuzko erlatibozkoak [SR] eta objektuzko erlatibozkoak [OR]), oinarrizko hitz-hurrenkera duten esaldi kanonikoak (SVO gaztelaniaz eta SOV euskaraz) eta galdetzailea duten NZ-galderak (subjektuzkoak [SQ] zein objektuzkoak [OQ]). 4. taulan ikus daitezke morfosintaxia ebaluatzeko ariketa bakoitzaren diseinu eta materialei dagozkien zehaztasunak, esaldi mota bakoitzeko adibideak barne. 
4. taula. Maila morfosintaktikoa ebaluatzeko ariketa esperimentalen inguruko zehaztasunak ${ }^{2}$.

\begin{tabular}{|c|c|c|c|c|c|}
\hline Ariketa & Diseinua & Aldagaiak & $N$ & Adibidea euskaraz & Adibidea gaztelaniaz \\
\hline Erlatibozkoen & \multirow{3}{*}{$\begin{array}{l}\text { Friedmann \& } \\
\text { Novogrodsky } \\
(2004)\end{array}$} & SR & 20 & Pinguinoa garbitzen duen umea & El niño que está limpiando al pingüino \\
\hline \multirow{2}{*}{$\begin{array}{l}\text { Erlatibozkoen } \\
\text { ulermena }\end{array}$} & & OR & 20 & Pinguinoakgarbitzen duen umea & El niño que está limpiando el pingüino \\
\hline & & Kanonikoak & 40 & Umeak pinguinoagarbitzen du & El niño está limpiandoal pingüino \\
\hline $\begin{array}{l}\text { Galde-perpausen } \\
\text { ekoizpena }\end{array}$ & \multirow{2}{*}{$\begin{array}{l}\text { Jakubowicz (2005), } \\
\text { L.. Tuller, C. } \\
\text { Jakubowicz \& M.J. } \\
\text { Gutierrez- } \\
\text { Mangadok egokitua }\end{array}$} & SQ & 12 & Nork orrazten du erregina? & ¿Quién está peinando a la reina? \\
\hline $\begin{array}{l}\text { Galde-perpausen } \\
\text { ulermena }\end{array}$ & & OQ & $\begin{array}{l}12 \\
\text { (24 ekoizp.) }\end{array}$ & Nor orrazten du erreginak? & ¿A quién está peinando la reina? \\
\hline
\end{tabular}

NZ-galderak elizitatzeko, eszena sinple bat irudikatzen zuen koloretako irudi bat aurkezten zitzaien ordenagailuko pantailan. Eszena horretan, elementu bat ezabatuta zegoen. Ikertzaileak elementu ezezagun horri erreferentzia egiten zion esaldi bat ekoizten zuen, eta, ondoren, parte-hartzaileei ekoitzarazten zitzaien falta zen elementua asmatzeko galdera bat. Horren ondoren, ikertzaileak lehen irudian ezabatuta zegoen elementua zekarren beste irudi bat erakusten zuen. Ikus (1)-eko adibidea, OQ baten elizitazioaren erakusgarri.

(1) Ikertzaileak: Begira, hemen jirafak rodillo bat dauka eskuan margoarekin. Zerbait margotzen du, baina ez dakigu zer, tapatuta dago. Galdetuidazu! Gero ikusiko dugu zer margotzen duen! Galdetuidazu!

Xede-erantzuna (OQ): «Zer margotzen du jirafak?»

Ikertzaileak: (hurrengo orrialdeko irudia erakutsi ondoren) Begira, zuhaitz bat margotzen du.

Erlatibozko perpausak ekoitzarazteko ariketan, esaldi kanonikoak eta subjektuzko eta objektuzko erlatibozko perpausak ekoitzarazi zitzaizkien. Ariketa horretan, bi pertsonaia ekintza berbera egiten irudikatzen zuten irudi bikote alderantzikagarriak aurkezten zitzaizkien parte-hartzaileei. Ikertzaileak irudi horiek deskribatzen zituen, eta parte-hartzaileei eskatzen zien pertsonaia horietako bat deskribatzeko (2).

(2) Ikertzaileak: Hemen pinguino bat eta mutiko bat daude. Hemen mutikoak pinguinoa garbitzen du (goiko irudia erakutsiz). Hemen pinguinoak mutikoa garbitzen du (beheko irudia erakutsiz). Eta hau, ze pinguino da hau? (beheko irudiko pinguinoa erakutsiz). Xede-erantzuna (SR): «Mutikoa garbitzen duen pinguinoa».

\footnotetext{
2 Materialen euskal egokitzapena Gutierrez-Mangadok egin zuen, eta gaztelaniazkoa Munarrizek.
} 
NZ-galderen eta erlatibozko perpausen ulermena aztertzeko esaldiak eta irudiak parekatzeko ariketetan, ikertzaileak irudi bat deskribatzen zuen eta pertsonaia bat erakusteko eskatzen zien parte-hartzaileei (esaldi esperimentala erabilita). Parte-hartzaileek, orduan, esaldiari lotutako irudia erakutsi behar zuten (3).

(3) Ikertzaileak (ORa elizitatzeko): Bi marrazki hauetan ipotx bat eta printze bat dauzkagu. Kamara bat daukate. Hemengo ipotxak printzea filmatzen du (goiko irudia erakutsiz), eta hemengo honetan printzeak ipotxa filmatzen du (beheko irudia erakutsiz). Erakutsi printzeak filmatzen duen ipotxa.

Xede-erantzuna: beheko irudiko ipotxa erakustea.

\subsection{Datuen analisia}

Artikulu honetan azaldutako hiru ariketa-mota horien erantzunen artean bi motatako emaitzak zeuden: hitzen (irudiak izendatzeko ariketa) edo esaldien (irudiak deskribatzeko ariketak) ekoizpena eta irudien hautaketa. Zuzenketa-irizpideak ariketen araberakoak ziren.

Irudiak izendatzeko ariketan, erantzun mota eta kopuruak aztertu ziren. Erantzunak kodetzean egokitzat jo ziren, xede-erantzunaz gain, sinonimoak eta erantzun atzeratuak. Erantzun atzeratu gisa sailkatu ziren erantzun egokiaren aurretik makuluren bat ( $e, m$, bueno) edo determinatzailea (un $[a]$ ) zutenak. Hutsak honako bost kategoria hauetan multzokatu ziren, baina taxonomia zehatzago bati jarraituz kodetu ziren, lehen erantzuna aintzat hartuta [23]:

- Huts semantikoak: kategoria semantiko bereko hitzak (adb. zaldia; xede-erantzuna: «astoa»), edo hiponimo (ehunzangoa; xede-erantzuna «harra») zein hiperonimoak (instrumento musical; xede-erantzuna: «flauta travesera»).

- Huts lexikoak: itzulinguru edo objektuaren deskribapenak (donde se echan los cereales; xede-erantzuna: «cuencos»), beste hizkuntza batean ekoitzitako izenak (pitxarra; xede-erantzuna: «jarra»), etab.

- Huts fonologikoak: sasi-hasierak (cep/pillo de diemp de dientes) eta parafasia fonologikoak ${ }^{3}$ (kaskagorri; xede-erantzuna: «katagorri»).

- Ez-erantzunak: erantzunik ez ematea izena ez datorkiolako (Ay, este me suena y lo he visto, pero no sé cómo se llama) edo laguntza fonologikoa jaso ondoren ematea (co-como pone ahí las las uvas, no? Los los el mosto lo que sea, no? pues no sé... [un barr...] barril, barril).

\footnotetext{
3 Euskalkien araberako prozesu fonologikoak zituzten ekoizpenak zuzentzat jo ziren (adb. etxia «etxea»ren ordez).
} 
- Bestelako hutsak: bisualak, hots, itxuraz antzekoa den beste objektu bati dagozkionak (adb. boligrafo; xede-erantzuna: «lima»); pertseberazioak, hots, lehenago aurkeztutako irudi bati zegokion izena errepikatzea, etab.

Morfosintaxia ebaluatzeko ekoizpen-ariketetan, erantzun zuzentzat jo ziren xede-erantzunaren esaldiko osagai guztiak zituzten eta morfosintaktikoki akatsik ez zuten esaldiak. Esaldi okerren artean kodetu ziren hitz-hurrenkera desegokia zutenak (adb. galdetzailea aurrean ez zuten (4a) moduko galderak) edota ergatiboa bezalako kasu-marka (4b) edo aditz laguntzaile ezegokia zutenak. Ulermen-ariketetan, zuzentzat jo ziren irudi egokiaren hautuak esaldi esperimentalak lehen aldiz aurkeztean.

(4) a. e mutikoak e zer e bultzaten buz-bultzaten dau? (xede-erantzuna: «zer bultzatzen dau mutikoak?»)

b. e zein e lehortzen dau e hipo-hipopotamuak? (xede-erantzuna: «zeinek lehortzen dau hipopotamua?»)

Artikulu honetan zehar aurkezten diren estatistika inferentzialeko analisietarako chi-square testak egin ziren.

\section{EMAITZAK}

Jarraian, AFrengan hiztegi-mailan azaleratutako arazo nagusiak aurkezten dira; eta, ondoren, maila morfosintaktikoan azaleratutako sintomak.

\subsection{Hiztegia}

Irudiak izendatzeko ariketan agerian gelditu zen AFk lexikoa berreskuratzean zenbait zailtasun zituela euskaraz eta gaztelaniaz. 1. irudian ageri da kontrolak eta AFk gaztelaniaz eta euskaraz ariketa egitean emandako erantzunen banaketa. Erantzun egokien kopurua nabarmen handiagoa izan zen kontrolarengan AFrengan baino bi hizkuntzetan (gaztelaniaz \% 88.9 vs $\% 78.1, \chi^{2}=10.16, p<.01$; euskaraz $\% 88.5$ vs $\% 65.8, \chi^{2}=36.66$, $p<.0001)$. Erantzun egokien kopuru apalagoak eta egokien artean sailkatutako erantzun atzeratuen kopuruek ere (AFren kasuan kontrolarenean baino gehiago ziren gaztelaniaz, $p<.0001$ ) aditzera eman zuten AFk zenbait zailtasun zituela hitzak edo, zehatzago, hitzen irudikapen lexiko-fonologikoak eskuratzeko.

Hutsen banaketari dagokionez, AFrengan bi hizkuntzetan huts fonologikoak (5a) izan ziren nagusi, ondoren ez-erantzunak (5b) eta huts lexikoak (5c), eta, azkenik, huts semantiko bakanak (5d-5f). Huts semantiko 


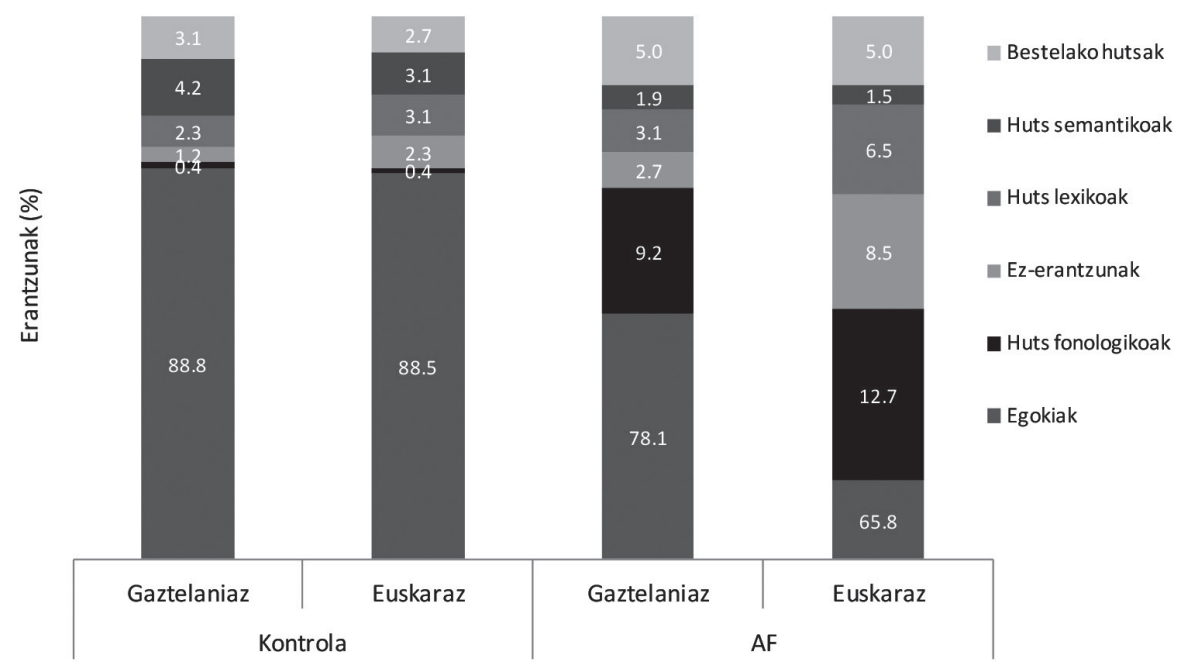

1.irudia. Parte-hartzaileen erantzunen banaketa izendatze-ariketan.

urriak ez ziren ezintasun semantikoaren adierazle: huts horietako batzuk bisualtzat ere (5e) jo litezke, eta beste batzuetan autozuzenketak ageri ziren ondoren $(5 \mathrm{f})$.

(5) a. eltzea (xede-erantzuna: «iltzea»)

b. $m$ eztakit eztakit (xede-erantzuna: «gurdia»)

c. donde se echan los cereales (xede-erantzuna: «cuenco»)

d. clarinete (xede-erantzuna: «flauta travesera»)

e. $a z a$ (xede-erantzuna: «letxuga»)

f. e zaldia ez astua (xede-erantzuna «astoa/astua»)

AFren eta kontrolaren huts-kopurua alderatuta, AFrengan gehiago ziren ez-erantzunak gaztelaniaz ( $\% 8.5$ vs $\left.\% 2.31, \chi^{2}=8.49, p=.0036\right)$ eta huts fonologikoak bi hizkuntzetan (gaztelaniaz $\% 9.23$ vs $\% 3.08, \chi^{2}=20.34$, $p<.0001$; euskaraz $\% 12.7$ vs $\left.\% 0.4, \chi^{2}=30.24, p<.0001\right)$. AFk izendatze-ariketan izandako jokabidea honako bi irudikapen-mailen urraduraren adierazletzat hartzen da: lexiko fonologikoa (ez-erantzunak) eta lexiko osteko maila fonologikoa (huts fonologikoak).

Oro har, AFren hutsen izaera kualitatiboki antzekoa izan zen gaztelaniaz eta euskaraz (1. irudia). Kuantitatiboki, berriz, euskaraz gaztelaniaz baino gutxiago ziren erantzun egokiak ( $\% 65.8$ vs $\% 78.1, \chi^{2}=9.15$, $p<.01)$; eta hutsen artean ere alde esanguratsuak aurkitu ziren ez-erantzunen kopuruan: euskaraz ez-erantzun gehiago ageri ziren gaztelaniaz baino $\left(\% 8.5\right.$ vs $\left.\% 2.7, \chi^{2}=7.16, p<.01\right)$. Hortaz, irudikapen lexiko-fonologikoa 
eskuratzean arazoak euskaraz eta gaztelaniaz agertuagatik, euskaraz larriagoak ziren.

\subsection{Maila morfosintaktikoa}

Erlatibozko perpausen eta galde-perpausen azterketak erakutsi zuen ariketa esperimental horien bidez, AFrengan zenbait zailtasun azaleratzen zirela modalitate eta hizkuntza jakin batean. Hasteko, perpaus horien ekoizpena elizitatzeko ariketetan AFren jokabidea kontrolarenaren antzekoa izan zen, ez zen inolako zailtasunik ageri (2. irudia). Ulermen-ariketetan emaitzak bestelakoak izan ziren: AFrengan ez zen ulermen-arazorik ageri gaztelaniaz, baina bai, ostera, euskarazko erlatibozkoetan eta galderazkoetan. Euskaraz esaldi-mota horiek ulertzeko zailtasun gehiago izan zituen gaztelaniaz baino, zuzentasun-mailak aditzera ematen zuenez (erlatibozkoe$\tan \% 57.5$ vs $\% 97.5, \chi^{2}=16.3, p<.0001$; galderetan $\% 54.2$ vs $\% 95.8$, $\left.\chi^{2}=11.79, p<.001\right)$.

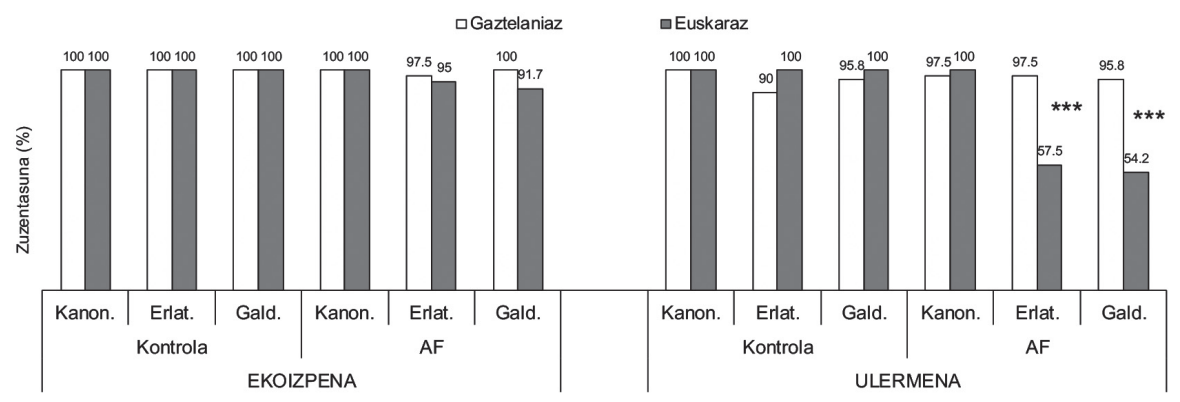

2. irudia. Kontrolaren eta AFren erantzunak ekoizpen- eta ulermen-ariketetan.

Ulermen-arazo horiek, gainera, espezifikoak ziren subjektuzkok eta objektuzko erlatibozkoen eta galde-perpausen arteko asimetriak aditzera ematen zuenez (3. irudia). AFk errazago ulertu zituen euskaraz objektuzko erlatibozkoak subjektuzkoak baino (\% 81 vs $\left.\% 31.6, \chi^{2}=8.03, p<.01\right)$, eta subjektuzko galderak objektuzkoak baino (\% 100 vs $\% 50, \chi^{2}=5.56$, $p<0.05)$. Kontrolaren jokabidearekin alderatzean ere nabarmena zen esaldi horiekin izandako zailtasuna ${ }^{4}$ OQetan $\% 100$ vs $\% 50, \chi^{2}=5.56, p<.05$; SRetan \% 100 vs \% 31.6, $\left.\chi^{2}=17.56, p<.0001\right)$.

4 3. irudian ez dira kontrolaren datuak ageri, argiago erakusteko, baina \% 100eko zuzentasuna izan zuen esaldi-mota horietan guztietan. 


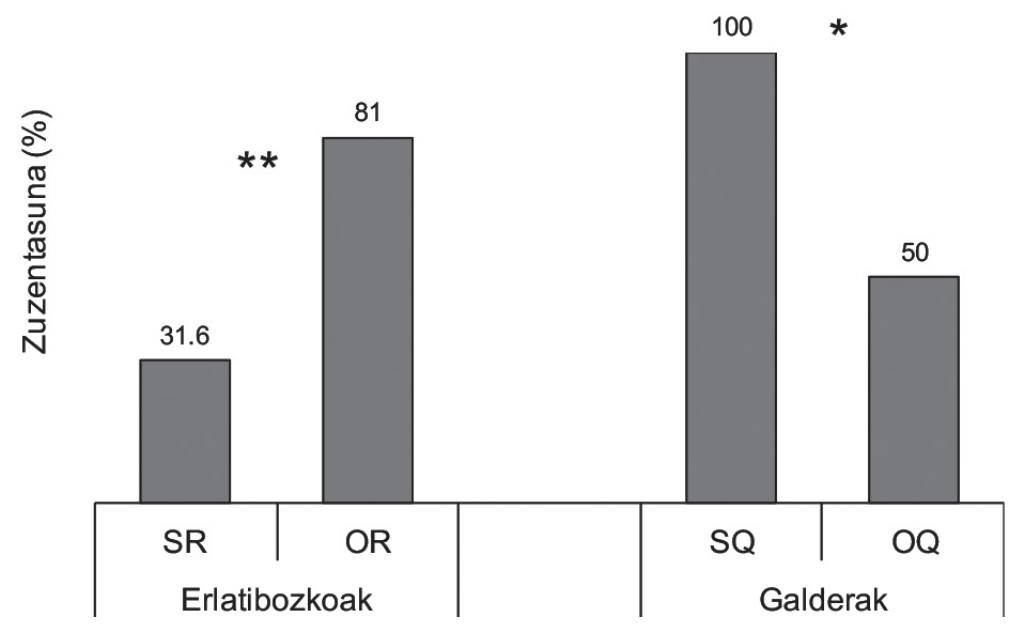

3. irudia. AFren erantzun zuzenak euskaraz ulermen-ariketetan egitura-moten arabera.

\section{EZTABAIDA}

Hemen aurkeztutako tesiaren helburu nagusia zen burmuin elebidunean hizkuntzek eta hizkuntza-osagaiek duten antolaketa edo arkitekturaren berri ematea. Horretarako ebidentzia bila, euskara-gaztelania afasiko elebidun baten kasu-azterketa egin zen. Emaitza nagusiak literaturakoekin eztabaidatzeko, ikerketa-galdera nagusietara itzuliko gara.

Batetik, afasia-sintomak euskaraz eta gaztelaniaz nolakoak diren galderari helduz, afasiaren sintomek ez diete modu orokorrean eragiten hizkuntza-maila, -egitura, eta -modalitate guztiei. Hala ikusi zen bi hizkuntzetan material berberak erabilita hizkuntza atal eta modalitateak xeheki aztertuta. Hiztegiari dagokionez, izendatze-ariketako emaitzek aditzera eman zuten AFrengan maila semantikoa urratu gabe zegoela, eta, aldiz, irudikapen lexiko-fonologikoak eta lexiko osteko irudikapen fonologikoak urratuta zeudela. Emaitza horiek berretsi ziren lagin zabalago bat aintzat hartuta, hots, hitzak berreskuratzea eskatu zioten ariketa guztietako (hizketa espontaneoa, irakurketa ozena, errepikapena) emaitzei erreparatuta [1]. AFrengan esanahiari dagokion irudikapen semantikoa osorik agertzeak eta formari dagokion irudikapen fonetiko-fonologikoan zailtasunak azaleratzeak berresten du esanahia eta forma disoziatuta daudela hizkuntzaren irudikapenean [7-9, 24]. Hala, bi maila horien arteko bereizketa patologiak ekoizpen-sistemari era globalean eragiten diola proposatzen duen Globaltasunaren Hipotesia [25] deritzonaren aurkako argumentua da, urradura espezifikoak aurkeztu dituzten beste lan batzuekin batera [7-9] . 
Morfosintaxian ere, urradura espezifikoak azaleratu ziren, aurreikusi bezala. Erlatibozkoen eta galde-perpausen ekoizpen-ariketa esperimentaletan ez zen ageri urraduraren adierazlerik AFrengan, ez gaztelaniaz ez euskaraz, nahiz eta hizketa espontaneoan eta ekoizpen-ariketa libreagoetan zenbait sinplifikazio eta saiheste-estrategia antzeman [1]. Aldiz, ulermenariketa esperimentaletan, euskaraz soilik ageri ziren arazoak, eta oso egitura zehatzetan: objektuzko galderak eta subjektuzko erlatibozkoak. Emaitza horiek aditzera ematen dute AFk agramatismo-forma erresidualen bat zuela. Galderetako subjektu-objektu asimetriaren norabidea (objektuzkoak kaltetuago) hainbat hizkuntzatan aurkitutakoarekin bat dator [26, 27]. Erlatibozkoetako ORekiko lehentasuna, berriz, erlatibozko esaldi postnominalak dituzten hizkuntzetan aurkitutako huts-ereduaren alderantzizkoa da. Alabaina, emaitza bat dator erlatibozko prenominalak dituzten beste hizkuntza batzuetako afasikoen jokabidearekin [28] zein euskaldun heldu osasuntsuen prozesamenduarekin $[29,30]$ eta garapen tipikoa duten haurren ulermenarekin [31]. Erlatibozkoen eta galderazkoen asimetrien azalpena ergatibo kasu-markaren baliagarritasunaren bidez azal litekeela proposatu izan dute Munarrizek eta bestek [32]; ulermenerako pista baliagarria izan daiteke egilea den argumentua identifikatzeko, baina ekoizpenean akatseragile gertatzen da.

Bestetik, gure bigarren ikerketa-galderari helduz, hots, afasiaren sintomak modu eta neurri berean azaleratzen diren elebidunen bi hizkuntzetan, AFren azterketak hauxe erakutsi zuen: antzekotasun kualitatiboak egon arren, antzekotasun eta alde kualitatibo eta kuantitatiboak zeudela, hizkuntza-maila eta -modalitateen arabera. Antzekotasun kualitatiboak aurkitu ziren hiztegi-mailako arazoetan (irudikapen semantikoa osorik bietan, eta fonologikoak urratuta bietan; ikus [33] ere maila fonologikoan azaleratutako urradurarako). Antzekotasun horiekin batera, alde kuantitatiboak ere ageri ziren hiztegian; hutsak gehiago ziren euskaraz (maila lexiko-fonologikoan eta lexiko osteko maila fonologikoan). Maila morfosintaktikoan, alde kualitatiboak gailentzen ziren: ulermen-arazoak euskaraz bakarrik antzeman ziren. Hortaz, AFk berreskuratze ez-paraleloa du; gaztelania hobeto mantendu edota berreskuratu du euskara baino. Berreskuratze-ereduetan eragiten duten faktoreak aintzat hartuz gero, bi hizkuntzen artean dagoen desberdintasunean honako bi faktore hauek eragina izan zezaketelakoan gaude: hizkuntza-errehabilitazioa, eta lesioaren ondorengo erabilera, bietan hala bietan gaztelania izan baita nagusi AFren kasuan. Aurreikuspenen araberako AFren jokabide ez-paraleloak, Adrover-Roigek eta bestek [21] aztertutako euskara-gaztelania elebidunaren nahasmendu ez-paraleloak eta tipologikoki desberdinak diren hizkuntzak dituzten elebidun afasikoen emaitzek [20, 34, 35] honako hau berresten dute: hizkuntzen arteko distantzia nahasmendu- eta berreskuratze-ereduetan eragin handikoa dela. Oro har, ikerlan honetako emaitzek, afasiaren ikerkuntzako beste ebidentzia batzuekin bat, erakusten dute bi hizkuntzak eta hizkun- 
tza-osagaiak hein batean neurofuntzionalki bereizita daudela elebidunaren burmuinean. Horregatik gerta daiteke hizkuntzak eta hizkuntza-osagaiak modu bereizian eta desberdinean eraginda suertatzea [5]. Hemen aztertutako hau kasu-azterketa da, eta komenigarria izango litzateke etorkizunean euskara-gaztelania elebidunak diren beste afasiko batzuk aztertzea. Horrek aukera emango luke kasu-azterketek dituzten mugei aurre egiteko eta AFren kasuan aurkitutako emaitzen orokortasun-maila aztertzeko. Emaitzen interpretazioak eta alderaketak bermatzeko, gainera, guztiz beharrezkoa da jokabidean eragiten duten aldagai psikolinguistikoak aintzat hartuta sortutako tresna eta material estandarizatuak garatzea euskaraz eta afasiko euskaldunak ebaluatzeko baliatzea [36].

\section{ONDORIOAK}

Ikerlan honen ondorio nagusiak honako bi hauek dira. Batetik, afasiak modu espezifiko eta bereizian eragin diezaieke hizkuntza-maila, -osagai eta -prozesuei. Disoziazioak aurkitu dira, bai maila lexikoan (esanahiaren eta formaren artean, kasu) eta baita maila morfosintaktikoan ere (SR vs OR eta SQ vs OQ). Bestetik, burmuin elebidunari helduta, afasiak modu desberdinean kaltetu ditzake elebidunen hizkuntzak, eta berreskuratzea ere desberdina izan daiteke hizkuntza horietako bakoitzean. Aipatutako bi ondorio horiek egiaztatzen dute hizkuntzak eta hizkuntza-osagaiak hein batean behintzat bereizita daudela burmuin elebidunean. Bestela esanda, sistema beraren barneko azpisistemak dira; eta, horregatik gerta daiteke burmuineko lesioen ondorioz modu bereizian urratzea. Azkenik, aurretik laburbildutakoaren harira, kasu-azterketa honek berretsi du ezinbestekoa dela hizkuntza eta hizkuntza-osagai guztiak zehaztasunez ebaluatzea hiztun elebidun eta eleaniztunengan, hizkuntza edo hizkuntza-osagai bat(zu)en balizko urradura oharkabean ez pasatzeko. Ildo beretik, etorkizunari begira, euskara-gaztelania afasikoen irudia osatze aldera hizkuntzen ezaugarriak (hizkuntzen arteko egiturazko [des] berdintasunak) eta hizkuntzaz kanpoko ezaugarriak (inguruko hizkuntzak zein diren, afasikoen hizkuntzen erabilera, terapiarako hizkuntza[k] etab.) ongi aztertu eta kontrolatzearen garrantzia nabarmendu da.

\section{ESKER ONAK}

Eskerrak eman nahi dizkiet EHUko Euskara Errektoreordetzari eta Euskaltzaindiari euskara akademikoa sustatzeko Euskarazko Tesien V. Koldo Mitxelena sariak antolatzeagatik. 2017an jasotako sari hori hein handi batean M.J. Ezeizabarrena irakaslearen lanari zor diot, beraren gomendio, ohar eta iruzkinekin nire tesia ontzeagatik. Eskerrak eman nahi dizkiet, ha- 
laber, ikerketa honetako parte-hartzaileei, eta artikulu honen orraztaileei. Artikulu honen oinarria izan den tesia [1] Eusko Jaurlaritzaren doktorego aurreko beka bati esker egin zen (BFI06.65), eta artikulua honako ikerketaproiektu hauen laguntzarekin burutu da: Eusko Jaurlaritza (IT-983-16), eta MINECO/FEDER (FFI2015-68589-C2-1-P).

\section{BIBLIOGRAFIA}

[1] MUNARRIZ, A. 2015. Hizkuntzen antolaketa burmuin elebidunean: gaztelania-euskara elebidun afasiko baten kasu-azterketa. UPV/EHU.

[2] MUNARRIZ, A. 2016. "Afasia hizkuntzen antolaketarako erakusleiho». Ekaia, 30, 185-95.

[3] LEVELT, W.J.M., ROELOFS, A. eta MEYER, A.S. 1999. «A theory of lexical access in speech production». Behavioral and Brain Sciences, 22, 1-75.

[4] GRODZINSKY, Y. 2000. «The neurology of syntax: Language use without Broca's area». Behavioral and Brain Sciences, 23, 1-71.

[5] PARADIS, M. 2004. A Neurolinguistic Theory of Bilingualism. John Benjamins, Amsterdam/Philadelphia.

[6] LAINE, M. eta MARTIN, N. 2006. Anomia: Theoretical and Clinical Aspects. Psychology Press, Hove.

[7] CARAMAZZA, A., PAPAGNO, C. eta RUML, W. 2000. «The selective impairment of phonological processing in speech production». Brain and Language, $\mathbf{7 5}, 428-50$.

[8] CUETOS, F., AGUADO, G. eta CARAMAZZA, A. 2000. «Dissociation of semantic and phonological errors in naming». Brain and Language, 75, 451-60.

[9] GOLDRICK, M. eta RAPP, B. 2007. «Lexical and post-lexical phonological representations in spoken production». Cognition, 102, 219-60.

[10] BASTIAANSE, R. eta THOMPSON, C.K. (ed.) 2012. Perspectives on Agrammatism. Psychology Press, New York.

[11] MENN, L. eta OBLER, L.K. 1990. Agrammatic aphasia: a cross-language narrative sourcebook. John Benjamins, Philadelphia.

[12] PARADIS, M. 2001. «The need for awareness of aphasia symptoms in different languages». Journal of Neurolinguistics, 14, 85-91.

[13] ALBERT, M.L. eta OBLER, L.K. 1978. The bilingual brain. Neuropsychological and neurolinguistic Aspects of Bilingualism. Academic Press, New York.

[14] PARADIS, M. 2001. «Bilingual and polyglot aphasia». In BERNDT, R.S. (ed.). Language and aphasia. 69-91, Elsevier Science, Amsterdam.

[15] GREEN, D.W., GROGAN, A., CRINION, J., ALI, N., SUTTON, C. eta PRICE, C.J. 2010. «Language control and parallel recovery of language in individuals with aphasia». Aphasiology, 24, 188-209. 
Hizkuntzak burmuin elebidunean; zer erakusten du gaztelania-euskara elebidun afasiko baten kasu-azterketak?

[16] GIL, M. eta GORAL, M. 2004. « Nonparallel recovery in bilingual aphasia: Effects of language choice, language proficiency, and treatment». International Journal of Bilingualism, 8, 191-219.

[17] DE DIEGO BALAGUER, R., COSTA, A., SEBASTIÁN-GALLÉS, N., JUNCADELLA, M. eta CARAMAZZA, A. 2004. «Regular and irregular morphology and its relationship with agrammatism: Evidence from two Spanish-Catalan bilinguals». Brain and Language, 91, 212-22.

[18] HERNÁNDEZ, M., COSTA, A., SEBASTIÁN-GALlÉS, N., JUNCADELLA, M. eta REÑÉ, R. 2007. «The organization of nouns and verbs in bilingual speakers: A case of bilingual grammatical category-specific deficit». Journal of Neurolinguistics, 20, 285-305.

[19] GORAL, M., LEVY, E.S., OBLER, L.K. eta COHEN, E. 2006. «Cross-language lexical connections in the mental lexicon: evidence from a case of trilingual aphasia». Brain and Language, 98, 235-47.

[20] VENKATESH, M., EDWARDS, S. eta SADDY, J.D. 2012. «Production and comprehension of English and Hindi in multilingual transcortical aphasia». Journal of Neurolinguistics, 25, 615-29.

[21] ADROVER-ROIG, D., GALPARSORO-IZAGIRRE, N., MARCOTTE, K., FERRÉ, P., WILSON, M.A. eta ANSALDO, A.I. 2011. «Impaired L1 and executive control after left basal ganglia damage in a bilingual BasqueSpanish person with aphasia». Clinical Linguistics and Phonetics, 25, 480-98.

[22] SNODGRASS, J.G. eta VANDERWART, M. 1980. «A standardized set of 260 pictures: Norms for name agreement, image agreement, familiarity, and visual complexity.». Journal of Experimental Psychology: Human Learning and Memory, 6, 174-215.

[23] RODRÍGUEZ-FERREIRO, J., DAVIES, R., GONZÁLEZ-NOSTI, M., BARBÓN, A. eta CUETOS, F. 2009. «Name agreement, frequency and age of acquisition, but not grammatical class, affect object and action naming in Spanish speaking participants with Alzheimer's disease». Journal of Neurolinguistics, 22, 37-54.

[24] CAPLAN, D., VANIER, M. eta BAKER, C. 1986. «A case study of reproduction conduction aphasia I: Word production». Neuropsychology, 3, 99128.

[25] DELL, G.S., SCHWARTZ, M.F., MARTIN, N., SAFFRAN, E.M. eta GAGNON, D.A. 1997. «Lexical access in aphasic and nonaphasic speakers». Psychological Review, 104, 801-38.

[26] NEUHAUS, E. eta PENKE, M. 2008. «Production and comprehension of wh-questions in German Broca's aphasia». Journal of Neurolinguistics, 21, $150-76$.

[27] VARLOKOSTA, S., NERANTZINI, M., PAPADOPOULOU, D., BASTIAANSE, R. eta BERETTA, A. 2014. «Minimality effects in agrammatic comprehension: The role of lexical restriction and feature impoverishment». Lingua, 148, 80-94. 
[28] SU, Y.-C., LEE, S.-E. eta CHUNG, Y.-M. 2007. «Asyntactic thematic role assignment by Mandarin aphasics: A test of the Trace-Deletion Hypothesis and the Double Dependency Hypothesis». Brain and Language, 101, 1-18.

[29] CARREIRAS, M., DUÑABEITIA, J.A., VERGARA, M., DE LA CRUZPAVÍA, I. eta LAKA, I. 2010. «Subject relative clauses are not universally easier to process: Evidence from Basque». Cognition, 115, 57-66.

[30] LAKA, I., ERDOCIA, K., DUÑABEITIA, J.A., MOLINARO, N. eta CARREIRAS, M. Complex syntactic processing in very proficient non-natives elicits N400. Cognitive Neuroscience Society Meeting CNS. San Frantzisko 2011.

[31] GUTIERREZ-MANGADO, M.J. 2011. «Children's comprehension of relative clauses in an ergative language: the case of Basque». Language Acquisition: A Journal of Developmental Linguistics, 18, 176-201.

[32] MUNARRIZ, A., EZEIZABARRENA, M.-J. eta GUTIERREZ-MANGADO, M.J. 2016. «Differential and selective morpho-syntactic impairment in Spanish-Basque bilingual aphasia». Bilingualism, Language and Cognition, 19, 810-33.

[33] MUNARRIZ, A. 2015. «Irudikapen fonologikoa gaztelania-euskara afasia elebidunean». In EZEIZABARRENA, M.J. eta GOMEZ, R. (ed.). Eridenen du zerzaz kontenta Sailkideen omenaldia Henrike Knörr irakasleari (19472008), 437-56, UPV/EHU, Bilbo.

[34] DIÉGUEZ-VIDE, F., GICH-FULlÀ, J., PUIG-ALCÁNTARA, J., SÁNCHEZ-BENAVIDES, G. eta PEÑA-CASANOVA, J. 2012. «ChineseSpanish-Catalan trilingual aphasia: a case study». Journal of Neurolinguistics, 25, 630-41.

[35] KAMBANAROS, M. eta GROHMANN, K.K. 2012. «BATting multilingual primary progressive aphasia for Greek, English, and Czech». Journal of Neurolinguistics, 25, 520-37.

[36] MUNARRIZ, A. eta POURQUIÉ, M. 2017. «CAT: afasia aztertzeko tresnaren euskal egokitzapena». In ALEGRIA, I., LATATU, A., ORMAETXEBARRIA, M.J. eta SALABERRI, P. (ed.). II IkerGazte Nazioarteko Ikerketa Euskaraz: Giza zientziak eta artea. 80-7, Udako Euskal Unibertsitatea, Bilbo. 